\title{
EFEITO DO ENCHARQUE APÓS AQUECIMENTO INDUTIVO NA FORMAÇÃO DE REVESTIMENTO GALVANNEALED EM AÇOS BAKE HARDENABLE*
}

Aldo Henrique de Almeida Barbosa ${ }^{1}$ Sandra Goulart-Santos ${ }^{2}$

Resumo

Henrique Lacerda Eleutério ${ }^{3}$

Os modelos de tratamento de galvannealing, com encharque isotérmico após o aquecimento indutivo, permitem otimizar o aporte térmico para a formação de compostos intermetálicos Fe-Zn, o que contribui significativamente para a obtenção de revestimentos galvannealed-GA de elevada qualidade. Nesse estudo foi avaliado o efeito das condições de galvannealing na formação do revestimento GA sobre aços bake hardenable-BH. Foram realizadas, em escala de laboratório, simulações variandose o modelo de galvannealing, com ciclos isotérmicos e resfriamento imediatamente após o aquecimento indutivo, a temperatura de aquecimento, entre $525^{\circ} \mathrm{C}$ e $570^{\circ} \mathrm{C}$, e o tempo de encharque, até 20 segundos. Em todas as simulações, além dos ciclos completos foram realizadas, também, interrupções do tratamento ao longo da etapa de encharque, através de resfriamento brusco das amostras, com o objetivo de se avaliar a microestrutura do revestimento ao longo de todo o tratamento. Para a caracterização dos revestimentos foram realizadas análises de composição química, microestrutura, perfil de composição ao longo da camada e de aderência. Os resultados permitiram determinar as características da formação do revestimento GA sobre os aços $\mathrm{BH}$ e estabelecer condições de galvannealing para o processamento desses aços, de forma a obter microestruturas otimizadas para as aplicações mais exigentes.

Palavras-chave: Aço galvannealed; Tratamento de galvannealing; Galvanização a quente.

\section{EFFECT OF THE SOAKING AFTER THE INDUCTION HEATING ON THE GALVANNEALED COATING FORMATION ON BAKE HARDENABLE STEELS \\ Abstract}

The galvannealing treatment models, with isothermal soaking after the induction heating, enables the optimization of the heat input to form Fe-Zn intermetallic compounds, which contributes significantly to obtain high quality GA coatings. In this study, the effects of galvannealing conditions in the GA coating formation on $\mathrm{BH}$ steels were evaluated. Simulations varying the galvannealing model with isothermal and cooling cycles immediately after the induction heating, the heating temperature between $570^{\circ} \mathrm{C}$ and $525^{\circ} \mathrm{C}$ and the soaking time until 20 seconds were performed in laboratory scale. In all simulations, in addition to the complete cycles, incomplete cycles were also performed with discontinuations during the soaking step, by quenching the samples in order to evaluate the coating microstructure throughout treatment. To characterize the coatings, analysis of chemical composition, microstructure, quantitative depth profile and adhesion were performed. The results showed the characteristics of the GA coating formation on $\mathrm{BH}$ steels and established the galvannealing conditions for processing these steels, in order to obtain optimized microstructures for the most demanding applications.

Keywords: Galvannealed steel; Galvannealing treatment; Hot dip galvanizing.

1 Engenheiro Metalurgista, Doutor em Engenharia Metalúrgica e de Materiais, Pesquisador Especialista do Centro de Tecnologia Usiminas, Ipatinga, MG, Brasil.

2 Engenheira Química, Doutora em Engenharia Metalúrgica e de Materiais, Pesquisadora do Centro de Tecnologia Usiminas, Ipatinga, MG, Brasil.

3 Engenheiro Metalurgista, Pesquisador do Centro de Tecnologia Usiminas, Ipatinga, MG, Brasil. 


\section{INTRODUÇÃO}

Com entrada em operação da segunda linha de galvanização contínua (CGL2) na Unigal Usiminas foram introduzidas tecnologias para as quais se faz necessário desenvolver novos ciclos de galvannealing, de maneira a garantir a mesma qualidade dos produtos da primeira linha instalada (CGL1). Uma dessas novas tecnologias é a que promove encharque térmico após o aquecimento indutivo. Essa prática permite controlar o aporte térmico para formação dos compostos intermetálicos Fe-Zn, minimizando a formação das fases $\Gamma$ (gama) e $\zeta$ (zeta) no revestimento. Isso melhora a aderência ao substrato e a lubricidade do produto GA durante a sua conformação.

Em aços $\mathrm{BH}$ a influência do tratamento de galvannealing é ainda mais pronunciada, em função da sua reduzida reatividade aumentar a necessidade de um maior aporte térmico para a continuidade do processo [1]. Portanto, torna-se essencial estabelecer ciclos de galvannealing de aços $\mathrm{BH}$ adaptados às condições operacionais da CGL2. Para isso, foram realizadas simulações em escala de laboratório, utilizando-se um simulador do processo de galvanização por imersão a quente, variando-se as condições do tratamento térmico de galvannealing.

\section{MATERIAIS E MÉTODOS}

Para a realização do trabalho experimental foi amostrado, em escala industrial na condição laminado a frio, um aço $\mathrm{BH}$. Os ensaios consistiram em simulações dos processos de galvanização a quente, em um simulador do processo de galvanização a quente (HDPS-Hot Dip Process Simulator), variando-se o modelo de galvannealing (com ciclos isotérmicos e resfriamento após aquecimento indutivo, na etapa do processo de galvannealing chamada de transformação do revestimento"TR"), a temperatura de aquecimento indutivo- "TAl", entre $525^{\circ} \mathrm{C}$ e $570^{\circ} \mathrm{C}$, e o tempo de encharque, até $20 \mathrm{~s}$. Essas variações estão esquematicamente mostradas nas figuras 1a e 1b. Vale destacar que todas as condições de processamento até a imersão no pote de $\mathrm{Zn}$ foram mantidas constantes.

Além de amostras retiradas no pote de $\mathrm{Zn}$ e ao final dos ciclos totalmente processados, também foram realizadas interrupções do tratamento ao longo da etapa posterior à de aquecimento (nas condições mostradas na figura 1b), por meio de resfriamento com gás He até a temperatura ambiente, com o objetivo de determinar a evolução microestrutural do revestimento.

Para a caracterização dos revestimentos foram realizadas análises microestruturais, via microscopia eletrônica de varredura (MEV) com espectrometria de raios $X$ por dispersão de energia (EDS) ao longo das seções das amostras. O teor de Fe foi quantificado ao longo de toda a espessura da camada, através da média de três medições, em diferentes regiões da mesma amostra. Além disso, foram realizadas análises de composição química, via espectrometria de emissão ótica por plasma (ICP), e de aderência do revestimento ao substrato, via teste de $V$-bend.

A partir das concentrações de Fe foi possível determinar a proporção de cada fase $\mathrm{Fe}-\mathrm{Zn}$ presente nos revestimentos [2]. A determinação das fases foi feita associando-se os teores de Fe medidos nos revestimentos às concentrações de $\mathrm{Fe}$ das fases, obtidas pelo diagrama de equilíbrio termodinâmico $\mathrm{Fe}-\mathrm{Zn}$, considerando que a fase $\zeta$ contêm de $5 \%$ a $6 \%$ de Fe; $\delta$ (delta), $7 \%$ a $12 \%$ de $\mathrm{Fe} ; \Gamma_{1}$ (gama 1 ), $17 \%$ a $19 \%$ de $\mathrm{Fe}$, e Г, 23 a $28 \%$ de $\mathrm{Fe}[3]$. 


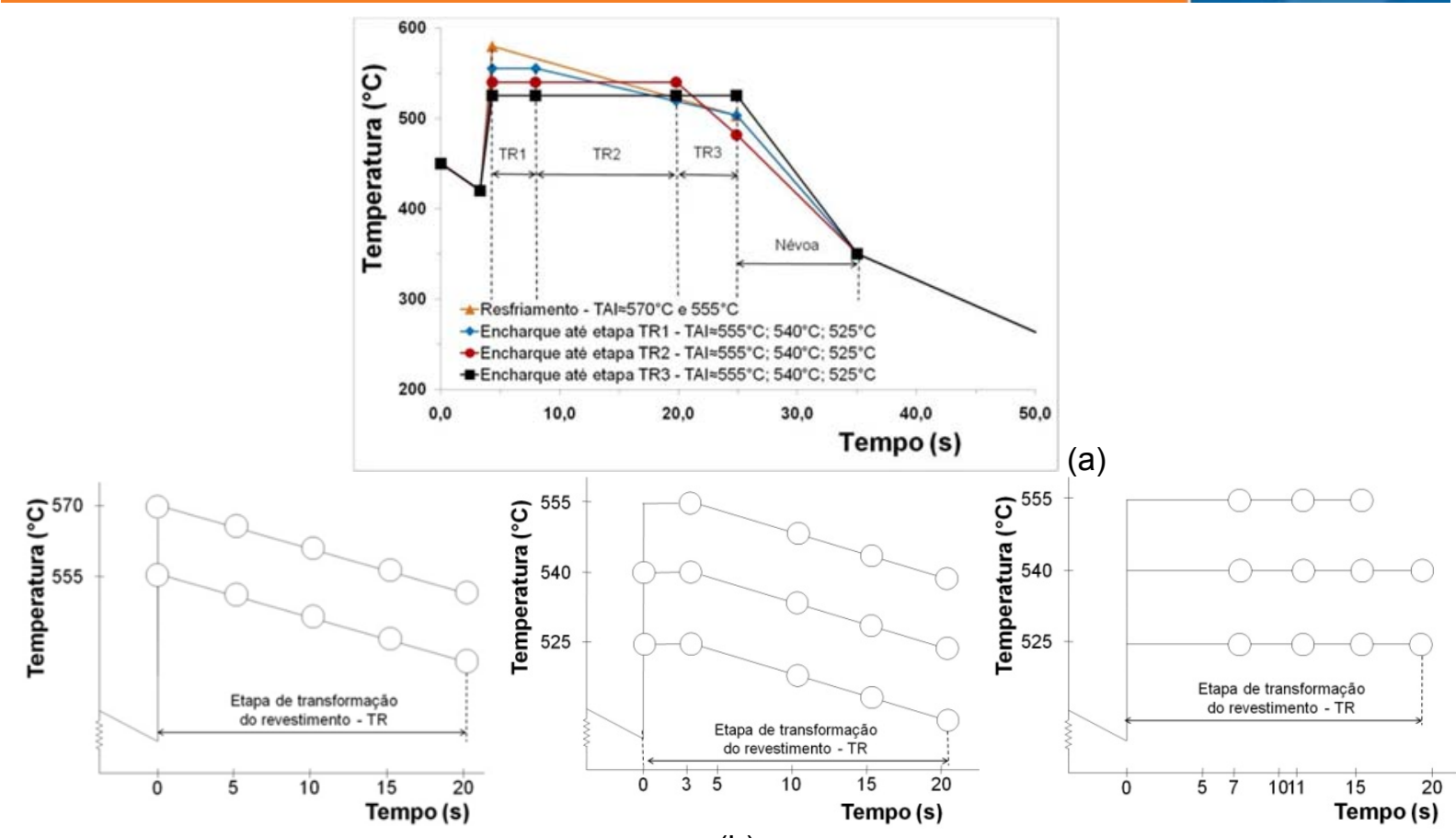

(b)

Figura 1. Ciclos de galvannealing esquemáticos, exemplificando: a) os modelos de tratamento avaliados (com e sem encharque) e, b) praticados nesse estudo, enfatizando a etapa de encharque.

Nesse estudo, a susceptibilidade à ocorrência de desplacamento foi associada à quantidade das fases $\Gamma$ e $\Gamma_{1}$ no revestimento. Essa determinação foi feita somando as quantidades dessas duas fases em suas respectivas regiões monofásicas às suas quantidades relativas nos campos bifásicos de $\left(\Gamma+\Gamma_{1}\right)$ e $\left(\Gamma_{1}+\delta\right)$, esse último com concentrações de Fe entre $12 \%$ e $17 \%$. Portanto, para efeito de associação com a aderência ao substrato, considerou-se, nesse estudo, a soma das quantidades das fases $\Gamma$ e $\Gamma_{1}$, independente de onde estejam localizadas na camada. Sob o ponto de vista de análise microestrutural, as fases $\Gamma_{\mathrm{e}} \Gamma_{1}$ foram consideradas separadamente.

\section{RESULTADOS E DISCUSSÃO}

\subsection{Revestimento Formado Antes do Tratamento de Galvannealing}

Na figura 2 são mostrados o aspecto morfológico e o perfil de concentração de $\mathrm{Fe}$ ao longo da espessura do revestimento formado após a imersão do aço por $3 \mathrm{~s}$ no banho de Zn. A difusão de Fe do substrato para o revestimento já se inicia no pote e com intensidade relativamente elevada. $\mathrm{Na}$ região cristalizada o teor médio de $\mathrm{Fe}$ varia entre aproximadamente $7,6 \%$ e 13,9\% (em massa), o que corresponde à formação dos compostos intermetálicos $\delta$ e $\Gamma_{1}$. Os cristais são normalmente pequenos (até $2,0 \mu \mathrm{m}$ ) e segmentados (não possuem uma formação compacta). Portanto, o que se visualiza como sendo uma única fase é, na realidade, um aglomerado de pequenos cristais com diferentes fases Fe-Zn.

De acordo com Barbosa [2], à temperatura de $460^{\circ} \mathrm{C}$ formam-se as fases $\zeta, \delta, \Gamma_{1}$ e a camada inibidora Fe/Al. A fase $\zeta$ surge em colônias de grãos compartilhando orientações com os grãos dos substratos, simultaneamente às formações da fase $\Gamma_{1}$ e da camada inibidora Fe/Al. Como não existe equilíbrio termodinâmico entre $\Gamma_{1}$ e o líquido, ou entre $\Gamma_{1}$ e $\zeta$, o surgimento de $\Gamma_{1}$ exigirá, necessariamente, a formação de $\delta$. Da mesma forma, não existe equilíbrio entre $\delta$ e líquido, fazendo com que a fase $\delta$ 
se forme na base de $\zeta$ e assuma o mesmo aspecto morfológico de $\zeta$ durante a solidificação. Ao final do processo $\zeta$ permanece na parte superior da região cristalizada, em contato com o líquido saturado em $\mathrm{Fe}$ (até 5,0\%) e, por isso, constituindo-se em uma camada descontínua. Abaixo, formam-se as fases $\delta$ e $\Gamma_{1}$.
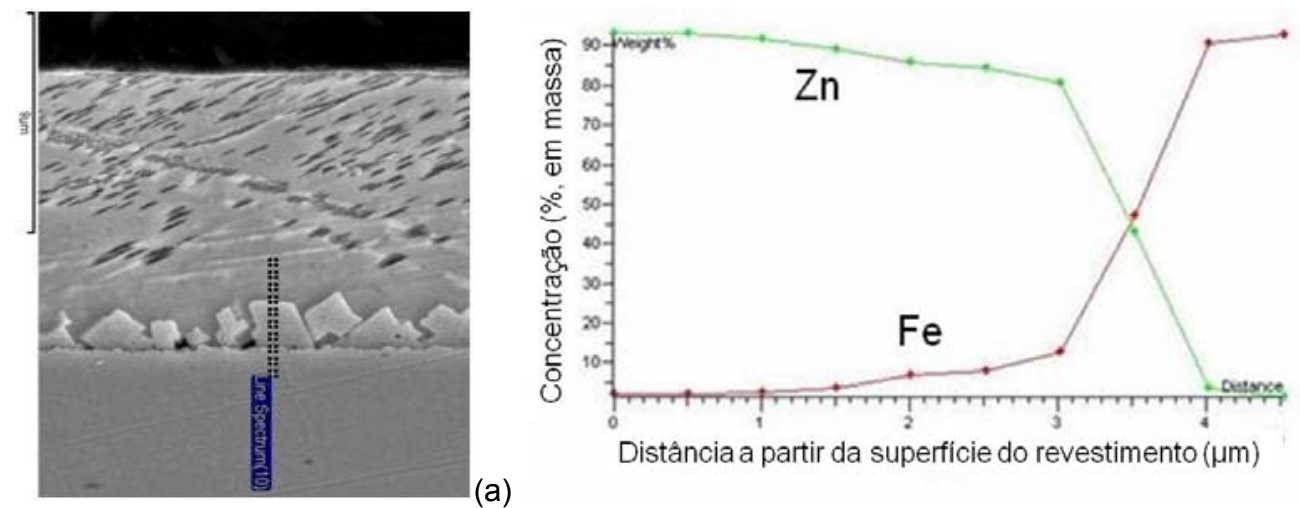

(b)

Figura 2. (a) Micrografia e (b) perfil de concentração de Fe ao longo da seção do revestimento, após imersão no pote de $\mathrm{Zn}$.

\subsection{Ciclo de Galvannealing com Resfriamento após Aquecimento Indutivo}

Nas figuras $3 a$ e $3 b$ são mostrados, respectivamente, os perfis de concentração de $\mathrm{Fe}$ ao longo da espessura dos revestimentos produzidos durante os tratamentos de galvannealing a $570^{\circ} \mathrm{C}$ e $555^{\circ} \mathrm{C}$. Nas duas primeiras amostras de ambas os tratamentos, até aproximadamente $5 \mathrm{~s}$ de galvannealing, os perfis de composição química foram relativos à camada cristalizada, o que significa dizer que o seu comprimento determina a espessura da camada de cristais Fe-Zn. Para as demais condições (com o prosseguimento do tratamento, acima de $5 \mathrm{~s}$ ), os perfis mostrados nessas figuras foram até $5 \mu \mathrm{m}$ da superfície do aço, por ser a região junto a interface com o substrato a de maior interesse para determinação da aderência.

$\mathrm{O}$ aporte de calor praticado com $570^{\circ} \mathrm{C}$ é tão intenso que, imediatamente após o aquecimento indutivo, a camada cristalizada alcança aproximadamente $1 / 3$ da espessura do revestimento ( $3 \mu \mathrm{m}$, para uma camada total de aproximadamente $10 \mu \mathrm{m})$, além de se formar a fase $\Gamma$ na interface com o substrato. A presença dessa fase no início do tratamento é prejudicial à qualidade do revestimento, em função do maior tempo que terá para crescer até o final do processo. Outro aspecto relevante é a menor proporção de fase $\delta$, significando que a mistura de cristais das fases $\Gamma, \Gamma_{1}, \delta$ e $\zeta$ em toda a camada, com propriedades distintas uma das outras, pode promover a nucleação e/ou facilitar a propagação de trincas no revestimento.

No ciclo de $555^{\circ} \mathrm{C}$, com menor aporte térmico comparativamente ao de $570^{\circ} \mathrm{C}$, a camada cristalizada imediatamente após a passagem da tira pelo aquecimento indutivo se torna menos espessa (aproximadamente $2 \mu \mathrm{m}$, figura $3 \mathrm{~b}$ ) e a formação dos compostos intermetálicos $\mathrm{Fe}-\mathrm{Zn}$ se inicia através de pequenas reações de outbursts (evidenciada pelo intenso crescimento da fase $\delta$ ). Além disso, não há um crescimento excessivo da fase $\Gamma$, até mesmo com o prolongamento do tempo na etapa posterior ao aquecimento ou nas amostras completamente processadas (independente do tempo decorrido na etapa de TR). Esse fato é relevante por flexibilizar o processamento desse material, permitindo alterações de velocidade da linha sem comprometimento da qualidade do produto.

Outra característica positiva na microestrutura de todos os revestimentos produzidos no ciclo com $555^{\circ} \mathrm{C}$ é a maior proporção de fase $\delta$, além de parte significativa da 
camada ser constituída somente por essa fase. A explicação está associada à presença dos outbursts desde o início do tratamento, formados em sua maior proporção pela fase $\delta$ [2]. A existência de uma região com predominância de uma fase, e essa ser mais dúctil que a da interface com o substrato, minimiza a nucleação e propagação de trincas no revestimento.

A análise dos ciclos completos confirma que a etapa de TR, após aquecimento indutivo, é a principal no tratamento de galvannealing, uma vez que os resultados nessa etapa se assemelham ao do produto final.

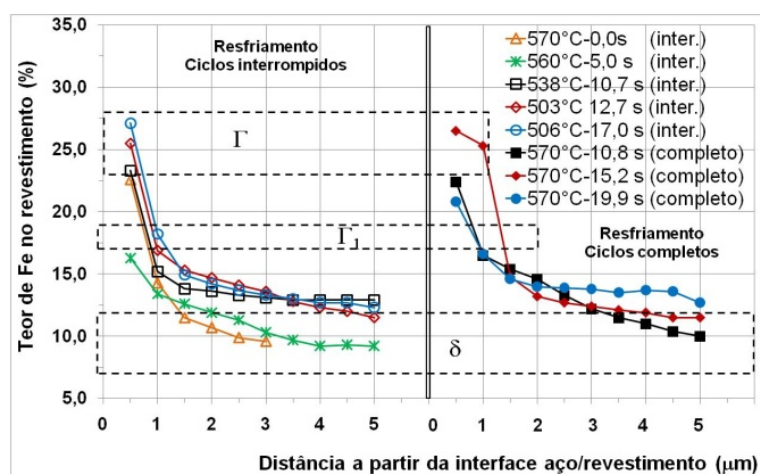

(a) $570^{\circ} \mathrm{C}$

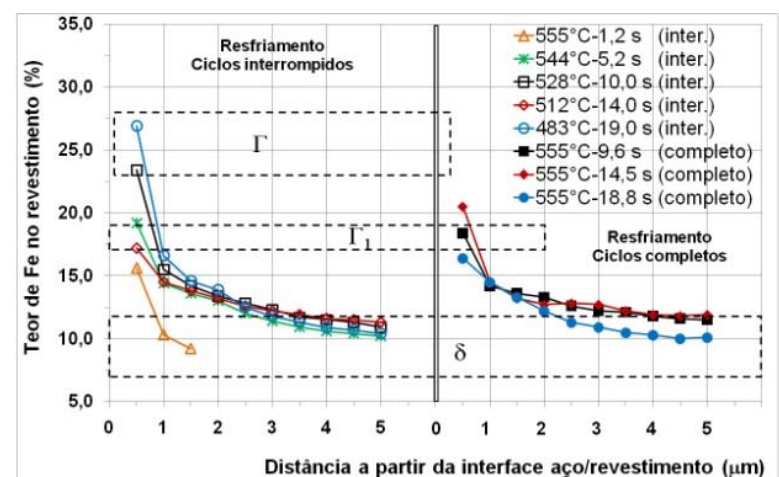

(b) $555^{\circ} \mathrm{C}$

Figura 3. Perfis de concentração de $\mathrm{Fe}$ ao longo da espessura dos revestimentos produzidos com tratamentos de galvannealing a (a) $570^{\circ} \mathrm{C} \mathrm{e} \mathrm{(b)} 555^{\circ} \mathrm{C}$.

A partir dos perfis de Fe mostrados na figura 3 foi possível determinar a espessura das fases $\left(\Gamma+\Gamma_{1}\right)$, figura $4 \mathrm{a}$, que pode ser relacionada à aderência do revestimento ao substrato. Vale lembrar que a quantificação dessas fases nesse estudo foi feita somando-se a espessura da camada relativa às concentrações de $28 \%$ a $17 \%$ de $\mathrm{Fe}$ à proporção de $\Gamma_{1}$ presente no campo bifásico $\left(\delta+\Gamma_{1}\right)$.

No tratamento a $570^{\circ} \mathrm{C}$ há um rápido crescimento desse somatório de fases $\left(\Gamma+\Gamma_{1}\right)$, ultrapassando já no início do tratamento (aproximadamente $5 \mathrm{~s}$ ) a espessura limite de 1,3 $\mathrm{mm}$, utilizada como referência de revestimento com boa aderência (para a espessura de aço avaliado nesse estudo). De acordo com Barbosa [2], esse forte crescimento da fase $\Gamma$ se deve ao fato de a faixa cristalizada alcançar a superfície do revestimento, quando acaba a solução de $\mathrm{Zn}$ líquida, empobrecida em Fe. A continuidade do processo difusional, mesmo no estado sólido, faz com que fases mais ricas em Fe cresçam em detrimento das demais.

No tratamento a $555^{\circ} \mathrm{C}$ a formação e crescimento de $\left(\Gamma+\Gamma_{1}\right)$ são bastante moderados, só ultrapassando a espessura máxima de referência $(1,3 \mu \mathrm{m})$ a partir de $14 \mathrm{~s}$ de tratamento na etapa de TR e mantendo-se próximo desse valor até mesmo no produto final.

A espessura das fases $\left(\Gamma+\Gamma_{1}\right)$ determina o limite superior da faixa operacional. $O$ limite inferior de processamento é determinado pela composição química da camada, sendo a faixa de $9,0 \%$ a $12 \%$ de Fe aquela referenciada como adequada ao uso.

A variação de composição química dos revestimentos tratados com ciclos de galvannealing a $570^{\circ} \mathrm{C}$ e $555^{\circ} \mathrm{C}$ é mostrada na figura $4 \mathrm{~b}$. Os comportamentos entre os dois ciclos são similares, apenas com teores um pouco inferiores no tratamento com menor aporte térmico. Associando-se os resultados de espessura das fases $\left(\Gamma+\Gamma_{1}\right)$, figura $4 \mathrm{a}$, aos de concentração de Fe no revestimento, figura $4 \mathrm{~b}$, é possível estabelecer uma janela de processamento. 


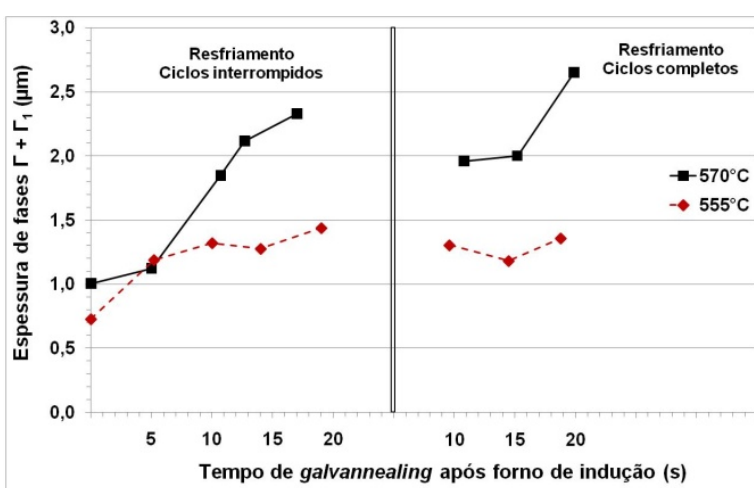

(a) $570^{\circ} \mathrm{C}$

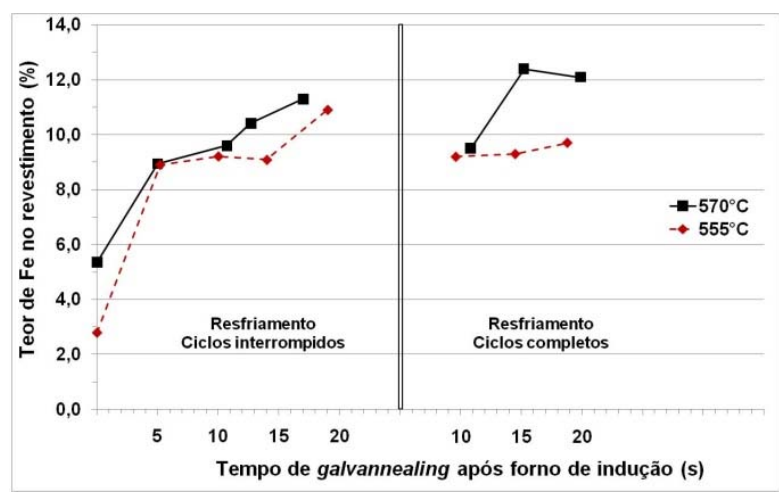

(b) $555^{\circ} \mathrm{C}$

Figura 4. (a) Espessura de fases $\left(\Gamma+\Gamma_{1}\right)$ e (b) teor médio de Fe em revestimentos produzidos com tratamentos de galvannealing a $570^{\circ} \mathrm{C}$ e $555^{\circ} \mathrm{C}$.

\subsection{Ciclo de Galvannealing com Encharque após Aquecimento Indutivo}

Nas figuras 5 e 6 são mostrados, respectivamente, os perfis de concentração de $\mathrm{Fe}$ ao longo da espessura da camada, as espessuras das fases $\left(\Gamma+\Gamma_{1}\right)$ e os teores de Fe nos revestimentos formados nos tratamentos de galvannealing com encharque de $3 \mathrm{~s}$ após aquecimentos com $555^{\circ} \mathrm{C}, 540^{\circ} \mathrm{C}$ e $525^{\circ} \mathrm{C}$.

O efeito térmico sobre a formação dos compostos intermetálicos Fe-Zn pode ser visualizado nessas figuras. $\mathrm{O}$ tratamento $\operatorname{com} 525^{\circ} \mathrm{C}$ e $3 \mathrm{~s}$ de encharque é insuficiente para garantir a total transformação do revestimento, independente do tempo que se aplique na etapa de TR. Nessa condição, embora a espessura das fases $\left(\Gamma+\Gamma_{1}\right)$ seja muito pequena $(<1,0 \mu \mathrm{m})$, figura $6 \mathrm{a}$, e constituída basicamente por $\Gamma_{1}$, a proporção de fase $\delta$ foi excessiva, figura $5 a$, e o teor de Fe (máximo de 8,0\%) muito abaixo do necessário para se garantir uma formação de fases equilibrada (figura $6 \mathrm{~b}$ ). A explicação está associada ao atraso na formação dos outbursts, que se formam somente ao final do encharque e não tem tempo e energia suficientes para que o prosseguimento da difusão de Fe permita o crescimento intenso das demais fases. Outro aspecto é a predominância da fase $\delta$ até bem próximo ao substrato, o que é maléfico do ponto de vista de propagação de trincas, por não existir uma camada $\Gamma_{1}$ acima da fase $\Gamma$ suficiente para absorvê-las. Com isso, pode propagar para a fase $\Gamma$, aumentando o risco de desplacamento.

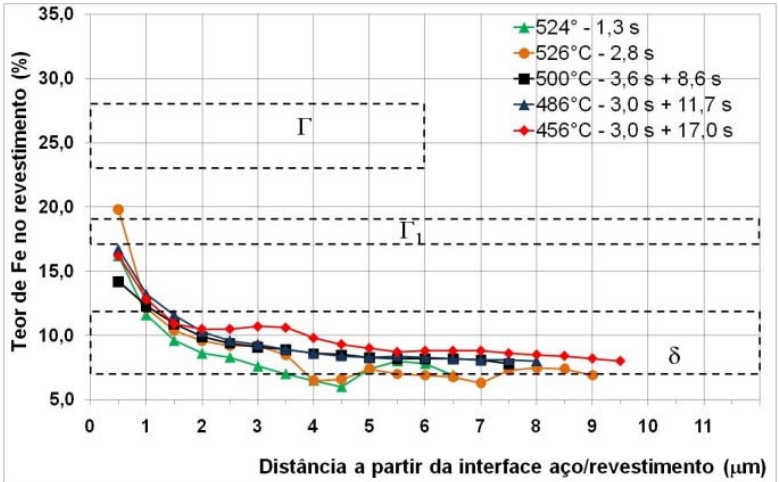

(a) $525^{\circ} \mathrm{C}$

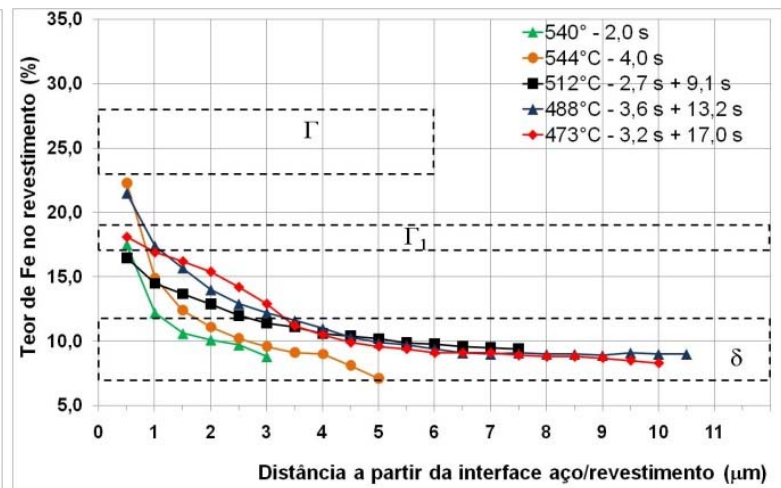

(b) $540^{\circ} \mathrm{C}$ 


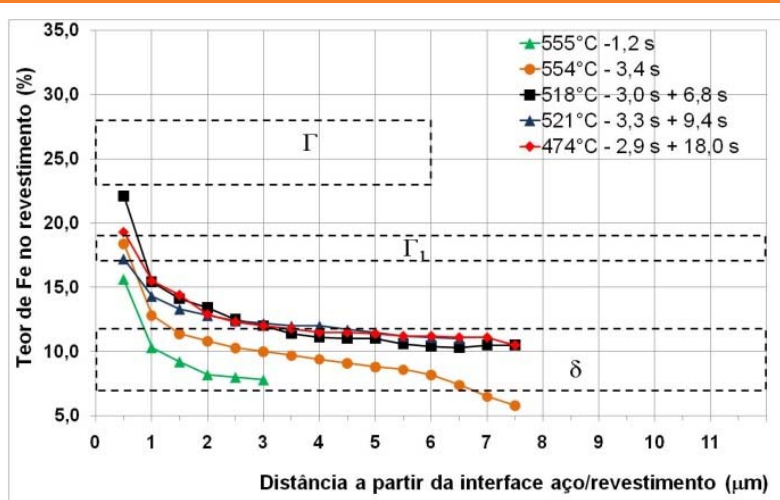

(c) $555^{\circ} \mathrm{C}$

Figura 5. Perfis de concentração de $\mathrm{Fe}$ ao longo da espessura dos revestimentos produzidos com tratamentos de galvannealing a (a) $525^{\circ} \mathrm{C}$, (b) $540^{\circ} \mathrm{C}$ e (c) $555^{\circ} \mathrm{C}$, todos com $3 \mathrm{~s}$ de encharque na TR.

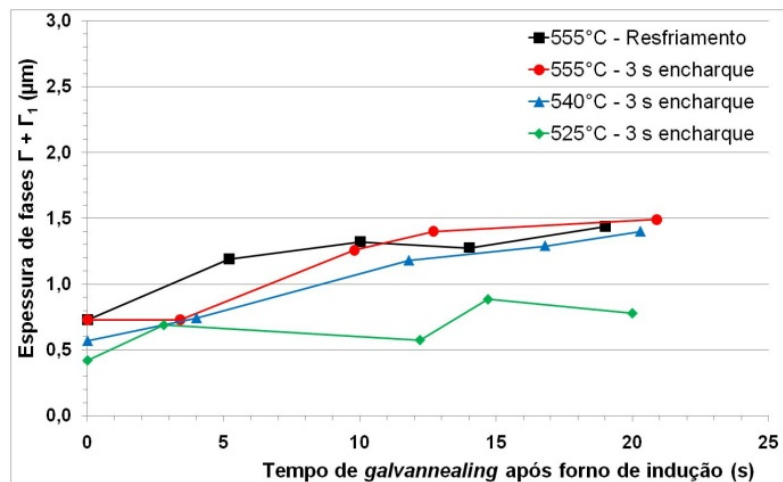

(a) Espessura de fases $\left(\Gamma+\Gamma_{1}\right)$

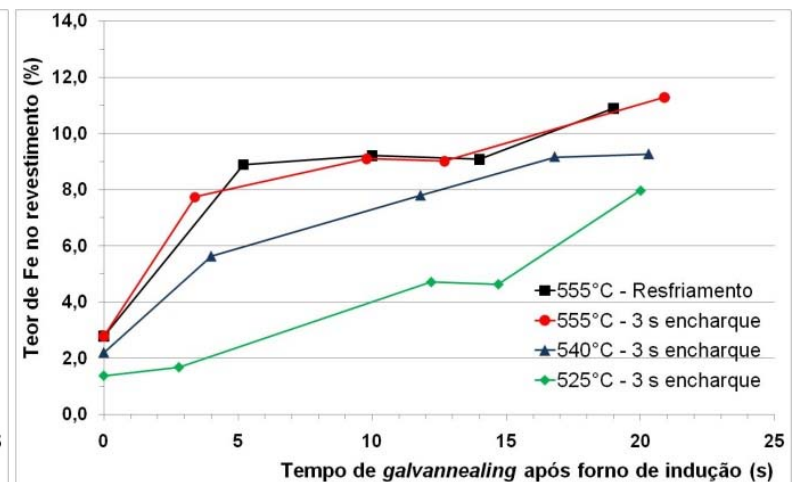

(b) Teor de Fe

Figura 6. (a) Espessura de fases $\left(\Gamma+\Gamma_{1}\right)$ e (b) teor de $\mathrm{Fe}$ em revestimentos produzidos com tratamentos de galvannealing a $555^{\circ} \mathrm{C}, 540^{\circ} \mathrm{C}$ e $525^{\circ} \mathrm{C}$, todos com encharque de $3 \mathrm{~s}$ após aquecimento.

Com o aumento da temperatura de galvannealing para $540^{\circ} \mathrm{C}$, imediatamente após a passagem da tira pelo aquecimento indutivo (figura $5 \mathrm{~b}$ ) nota-se uma estrutura mista, com uma faixa cristalizada mais espessa e outra com ocorrência de outbursts. Ao se formarem no início do processo, além do maior aporte de calor, há tempo suficiente para o crescimento das fases, reduzindo a quantidade de fase $\zeta$ na superfície e permitindo a existência de uma fase $\Gamma_{1}$ acima da fase $\Gamma$, minimizando a propagação de trincas no revestimento até o substrato.

Pelas figuras $5 b$ e $6 a$ há um aumento expressivo das fases $\Gamma_{1}$ e $\Gamma$ (essa última em menor proporção) com a elevação da temperatura de galvannealing de $525^{\circ} \mathrm{C}$ para $540^{\circ} \mathrm{C}$, mas apenas moderado com o tempo de resfriamento na etapa de TR, alcançando essas fases a espessura de $1,3 \mu \mathrm{m}$ com $16,8 \mathrm{~s}$ de processamento na etapa de TR (sendo 13,2 s de resfriamento e 3,6 s de encharque).

O teor de Fe superior a 9\% só foi alcançado com tempo de 16,8 s (figura $6 \mathrm{~b}$ ), tornando impróprios os tratamentos de galvannealing realizados com tempos inferiores a esse.

Além de uma espessura adequada das fases $\left(\Gamma+\Gamma_{1}\right)$, de uma menor proporção da fase $\Gamma$ e de um teor de $\mathrm{Fe}$ de $9,2 \%$, nota-se uma proporção mais equilibrada de fases $\Gamma$ e $\delta$, o que denota um revestimento completamente transformado, mas menos susceptível ao desplacamento.

Com temperatura de galvannealing de $555^{\circ} \mathrm{C}$ há um aumento na velocidade de crescimento dos cristais, mas com microestrutura (figuras $5 c$ e 6a) e composição química (figura $6 \mathrm{~b}$ ) muito semelhantes às obtidas com tratamento a $540^{\circ} \mathrm{C}$. Nessa 
temperatura de $555^{\circ} \mathrm{C}$, comparando-se os dois tipos de modelos de galvannealing, com encharque de $3 \mathrm{~s}$ e com resfriamento na etapa de TR, nota-se revestimentos com características morfológicas, químicas e microestruturais bastante semelhantes. As variações de espessura das fases $\Gamma+\Gamma_{1}$ e do teor de $\mathrm{Fe}$ nos revestimentos formados nos tratamentos com temperaturas de $555^{\circ} \mathrm{C}, 540^{\circ} \mathrm{C}$ e $525^{\circ} \mathrm{C}$ e encharques que variaram até $20 \mathrm{~s}$ são mostradas na figura $7 \mathrm{a}$ e $7 \mathrm{~b}$, respectivamente. De maneira geral, pode ser observado que os aumentos da temperatura de aquecimento e do tempo de encharque aceleram a formação do revestimento. Pela figura $7 a$ as fases $\Gamma+\Gamma_{1}$ aumentam constantemente com o tempo de encharque e que esse crescimento é significativamente maior em temperaturas mais elevadas.

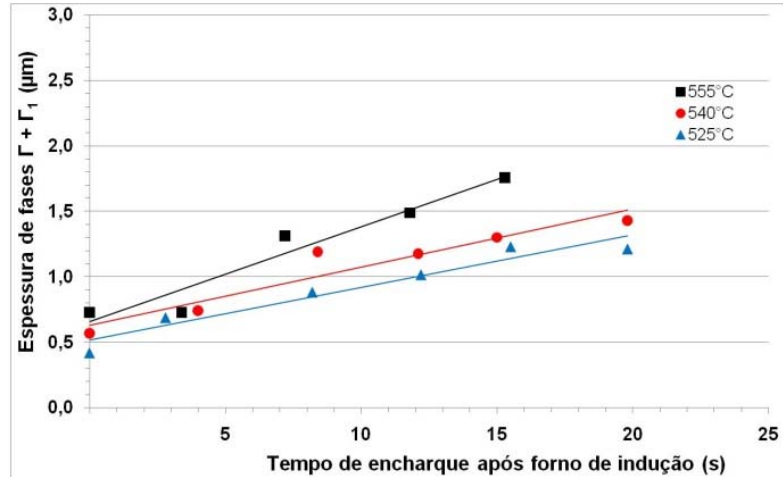

(a) Espessura de fases $\left(\Gamma+\Gamma_{1}\right)$

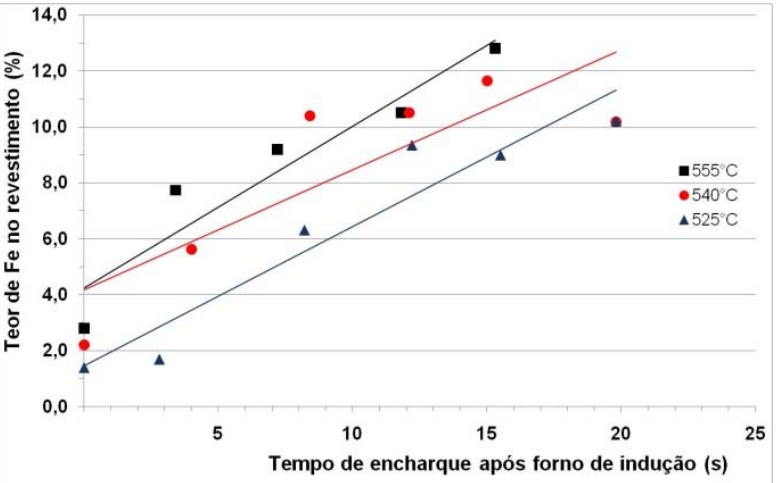

(b) Teor de Fe

Figura 7. (a) Espessura de fases $\left(\Gamma+\Gamma_{1}\right)$ e (b) teor de Fe em revestimentos produzidos com tratamentos de galvannealing a $555^{\circ} \mathrm{C}, 540^{\circ} \mathrm{C}$ e $525^{\circ} \mathrm{C}$, e encharque até $20 \mathrm{~s}$ após aquecimento.

\section{CONCLUSÃO}

É possível obter qualidades similares de revestimento adotando-se os modelos de galvannealing com resfriamento e com encharque na etapa posterior ao aquecimento indutivo.

Com relação à evolução microestrutural do revestimento os primeiros cristais de compostos $\mathrm{Fe}-\mathrm{Zn}$ no revestimento, constituídos pelas fases $\zeta, \delta$ e $\Gamma_{1}$, são formados ainda dentro do pote de $\mathrm{Zn}$. O efeito do aporte de calor é tão intenso que tratamentos acima de $555^{\circ} \mathrm{C}$ são inviáveis (independente do modelo de galvannealing praticado) pela formação da fase $\Gamma$ já imediatamente após 0 aquecimento indutivo. A presença dessa fase no início do tratamento é altamente deletéria à qualidade do revestimento, em função do maior tempo e intensidade que terá para crescer até o final do processo. A viabilidade dos ciclos de galvannealing com temperatura igual ou inferior a $555^{\circ} \mathrm{C}$ se deve à maior formação de fase $\Gamma_{1} \mathrm{em}$ detrimento da fase $\Gamma$.

De modo geral, a redução da temperatura de aquecimento indutivo minimiza a formação da fase $\Gamma$. Portanto, tratamentos com temperaturas mais baixas devem ser priorizados em detrimento aos de maior aporte térmico, o que deve ser compensado com o aumento do tempo de encharque na etapa após aquecimento.

\section{REFERÊNCIAS}

1 Barbosa AHA, Bouças CHS, Zacarias JJ; Vieira RR. Estudo da influência da temperatura no induction heating sobre a qualidade dos revestimentos galvanizados a quente, Relatório do Centro de Pesquisa da Usiminas, Março, 2007. 
2 Barbosa AHA. Efeito das condições de galvannealing na qualidade do revestimento galvanizado a quente GA formado sobre aços de alta resistência contendo $P$ e $B$, Tese de doutorado, Belo Horizonte: Universidade Federal de Minas Gerais, 2010.

3 Guttmann M. Diffusive phase transformation in hot dip galvanizing, Materials Science Forum, 1994, v. 155-156, p. 527-548. 